\title{
The benefit of introducing audit software into curricula for computer auditing students: a student perspective from the University of Pretoria
}

\author{
G P Coetzee \& R du Bruyn* \\ University of Pretoria
}

\begin{abstract}
The use of computers in the learning process is a well-researched area. The introduction of computers and related audit software in the auditing field has had a major influence on the auditing process. Very little research has been done on the inclusion of computer audit software in the auditing syllabus. Even less research has been done on the students' perspective of the benefits of the introduction of such software. To offset this shortcoming, the third-year computer-auditing students at the University of Pretoria were requested to complete a questionnaire.

The aim was to evaluate the students' perspective on the benefits, if any, for third year auditing students at the University of Pretoria, derived from the incorporation of practical computer training in an audit software package, in their syllabus

The results of the study clearly indicated that students are willing to sacrifice more of their time for practical computer classes because they are aware of the beneficial impact on their understanding of the subject as well as their future careers
\end{abstract}

\section{INTRODUCTION}

$\mathrm{T}$ he rapid changes during the last few decades in the computer technology environment have resulted in a need to change the way education happens (Boyce 1999; Davis 2000; Theron 1999).
With the increasing use of computers in the business world, the demand for accounting and auditing graduates with hands-on experience in computer business applications has increased dramatically (Davis 2000; Ahadiat 1992).

The practical training of students in the computer field is a necessity for accountants and auditors (Ahadiat 1992). As early as 1985, when a survey was conducted to identify computer competence requirements in the accounting industry, it was found that most accounting firms desire computer coverage in the curricula of accounting courses (Waller \& Gallum 1985). This survey indicated that it is essential to provide students in the accounting environment with the necessary hands-on training in accounting computer applications.

Use of computers in accounting education began in the early 1960s and since then the personal computer has become a prime choice in accounting education to equip students with practical accounting computer skills (Borthick \& Clark 1987). The objective of auditing is to evaluate the reasonableness of financial statements, thus determining if the financial statements properly reflect the performance of the business (SAICA 1998(a)). For the auditor to be able to fulfil this responsibility, relevant knowledge and skills should be obtained. Because financial statements, and therefore accounting, form the basis of external auditing, it is inevitable that auditing education should be utilising the computer as an educational tool. Although subject-related computer training (for example audit software applications that assist in drawing up working papers) is taking place, the benefit, scope and impact of it needs to be monitored continuously to ascertain whether it is appropriate for

\footnotetext{
${ }^{*}$ Contact Person:
}

Mr Rudrik du Bruyn, Department of Accounting, University of Pretoria, Pretoria, 0002

Tel: $\quad 012420-4074 / 0834566970$

Fax: $\quad 012362-5142$

e-mail: rudrik.dubruyn@up.ac.za 
training auditors in the skills and knowledge they require.

Without proper research, educators are not able to assess the effects of using the computer in the learning process. What the actual contribution to student knowledge and skills and the benefits resulting from learning on the computer in terms of future employers of students and the auditing profession's needs should be evaluated (Davis 2000). The measurement of student performance, the attitude of students, the relevance of computer skills to auditing practice, resources used and time spent are all topics which need to be researched (Borthick \& Clark 1987; Bagranoff 1993).

This study aims to evaluate the benefits, if any, for third year auditing students at the University of Pretoria, derived from the incorporation of practical computer training in an audit software package, into the syllabus. Most other tertiary institutions contacted by the authors, indicated that practical computer training was not part of the auditing syllabuses. The question arises whether students who are exposed to audit software in their syllabuses, feel they have an advantage over other students not exposed to the software. This study will be limited to identifying students' perceptions about the introduction of audit software into the computer-auditing syllabus. As students are clients of a university, it is important for the service provider to know what the clients perceptions and needs are.

The article is structured as follows:

- a literature review;

- a presentation and discussion of the results of a questionnaire completed by auditing students at the University of Pretoria.

\section{REVIEW OF PERTINENT LITERATURE}

A study of the literature pertinent to the topic of benefits of introducing audit software in the curricula for computer auditing students was performed. To make the results of this literature more accessible the literature was divided into three categories for discussion. Firstly the use of computers in the auditing environment was investigated, to determine whether a need exists to prepare students for the audit profession. The second category focuses on the use of computers in the learning process, to assess the relevance and benefits of this medium in the learning process. Finally, the use of computers in auditing education is reviewed, to determine current practices. In each of these categories, literature regarding students' perception was also investigated. By looking at the need for computer knowledge and skills in the auditing environment and focussing on students who use computers it will become clear that computer auditing programmes can be successfully used in the auditing classroom.

\section{Computers in the auditing environment}

Auditors need and in fact are forced to develop expertise in computer systems as a result of the change from manual to computerized systems and the availability of computers and computer software as an audit tool (Pettigrew 1991; Theron 1999). Auditors function in a highly competitive environment where computer technology forms the basis of today's business environment. Auditor's fees are based on the time involved in completing an audit, and audit tools are able to assist the auditor in minimizing time and costs. Businesses without proper computerised systems will not be able to survive in the modern global economy (Kiger \& Scheiner 1997).

Various contributors to the field have indicated that using computer software as an audit tool has specific advantages. Lanza (1998) is of the opinion that when performing an audit with audit software as a tool, no special data translation is required and file size is not limited. There are further advantages, as for instance, detailed auditing working papers are electronically generated, a time saving action; also there is consistency and uniformity in the standard working papers, while the cost of audit engagements is reduced. Lanza also points out a number of operational advantages. One is that a hundred percent audit coverage could lead to a more effective audit, which results in a better understanding of the client's business. Another is that the audit software enables the auditor to add value to the organization through operational audits. And a third advantage is that audit software is a powerful tool in fraud investigations when fraud is expected as it is easily used to identify unusual trends in data.

Nearon (2001), another thinker on the topic of computers in auditing is convinced that effective auditing, through the proper use of computerised systems, will reduce the cost of capital for organisations, leading to larger return on investments. This has benefits for the public. According to Paukowits (1998) the use of Computer Assisted Auditing Techniques (CAATS) has been reported to improve the morale of auditors because of the favourable impact learning new skills has on them.

The professional accounting and auditing bodies, as for example the Institute of Chartered Accountants of Scotland, have realized the advantages of including computer technology in the auditing profession. As early as 1991, that body implemented computerauditing courses in audit technology to address members' needs in the field (Pettigrew 1991). Generally Accepted Auditing Standards (GAAS) states that auditors are required to have an under- 
standing about underlying computerised systems as a basic competency (Watne \& Turney 1991). The International Federation of Accountants' (IFAC) has issued various guidelines on computer technology and auditing, for example Guideline number IEG 11 focuses specifically on computer technology in the accounting curriculum (IFAC 1996). The American Institute for Certified Public Accountants (AICPA) arranged that a technology issues task force consider the way in which auditing standards reflect the use and impact of computer technology (AICPA 1999). Our own South African Institute of Chartered Accountants has performed a similar exercise, which has led to the issuing of South African Auditing Standard (SAAS) 401 in 1998 - Auditing in a Computer Information Systems Environment (SAICA 1998(b)).

In the past, auditors' computer skills were limited to auditing around the computer (printing and scrutinizing the information) and using the computer as an administrative tool. The rapid growth in data volumes has increased the necessity for auditors to change their audit approach by involving powerful software applications in the execution of the audit. Today, software applications are widely used by auditors and it is essential for potential auditors (auditing students) to get the necessary exposure (Gelinas 2001; Davis 2000; Knechel 2000; Watne \& Turney 1991).

Because auditing is a logical process, and the auditor has to rely on his/her judgment, current trends in auditing are changing from overly structured methods, to a much more subjective, risk-based approach in which the auditor's judgment is even more taxed than before. Some methods used by auditors in this new approach include standardized audit programmes, statistical sampling methods, regression analysis, models for evaluating internal control, decision aids and expert systems (Gelinas 2001; Paukowits 1998). These normally time-consuming techniques are becoming an integral part of every audit. In modern auditing, computer technology forms the basis on which auditors function (Knechel 2000). Therefore it is critical that the skills needed to function in a computerised environment be integrated into auditing education.

A partnership is needed among audit firms, professional societies and the academic community to address the challenges facing auditors in their need for adequate computer technology skills (Nearon 2001). The literature on the topic emphasizes the need for computer skills in the auditing environment. Students need to be trained to cope in a computerised auditing environment.

The literature review yielded no work related to students' perspectives on the use of computers in the auditing environment.

\section{Computers in the learning process}

The starting point for an auditor to be successful in the profession is the learning of auditing concepts. As seen from the above literature study, these concepts should be incorporated in computer audit software. The South African Qualifications Authority (SAQA Act 1995), which formulates national education policy, states that outcomes-based education should form the basis of the learning process. Outcomesbased education aims to make learners ready for their careers after their studies.

A single teaching method cannot create all the conditions necessary for a given learning objective. Learning objectives involving complex skills require teaching methods that promote active learning on the part of students (Bonner 1999). Achieving the learning objectives related to computer auditing can be enhanced through active learning by the student and the use of audit software in conjunction with theoretical classes (Davis 2000; Hermanson et al 1999).

According to the Accounting Education Change Commission (1992), the learning process should include increased student involvement through the use of case studies, simulations and group projects. Knapp and Knapp (2000), show that the computer can be effectively used as a case study simulator by integrating $A C L$ audit software into the financial statement auditing class. The use of computer software for case studies in the classroom teaches students skills such as critical thinking, problem solving and analytical thinking (Knapp \& Knapp 2000). This is especially useful where learning strategies must be emphasized, where there is a need for understanding rather than memorization, and unstructured problems are addressed (Bagranoff 1993).

Although no literature was found on the students' perspective with regard to computers in the learning process, computers in the learning process has been widely researched. As this study focuses on the benefits (if any) of introducing audit software in the curricula for computer auditing students, the influence on learning theories and concepts, the measurement of the effects of the use of computers in the learning process and issues related to the introduction of computers in the learning process is briefly reviewed.

\section{Learning theories and concepts}

There are many reasons why the use of computers in the learning process might possibly improve education. One obvious advantage is that the burden of calculations shifts from the student to the computer. Borthick and Clark (1987) maintain that this easing 
up leads to improvements in concentration and time spent on other areas of study. Productive thinking is consequently better. Learning can be based on understanding rather that on memorizing (Wertheimer 1959). Creative thinking is enhanced if tedious calculations are not the largest part of the auditing process. The total thinking process involved in the production of ideas, and the creation or discovery of what is new, is satisfying to the user (Evans 1986). There is a certain directing of attention when the computer performs repetitive tasks for the learner. What is noticed becomes the signal for what is being done; controlling attention is a way of influencing behaviour (Guthrie 1959). Learning strategies, such as problem solving strategies and generally useful thinking skills are possible (Nickerson et al 1985).

In the non-cognitive areas of the learners' experiences in the classroom, such things as motivation, interest, self-esteem, confidence, satisfaction, attitudes, perseverance and willingness to take risks seem to be enhanced by use of computers in the classroom (Silver 1985). Learners' beliefs can influence their perceptions and cognition (Nisbett \& Ross 1980).

\section{Measurement of the effects of the use of computers}

Irrespective of the learning theory under investigation, the effects of the use of computers in the learning process may be measured against performance, student attitude and relevance to the practice of auditing. Studies have shown that an equivalent or better performance in examinations and other graded assignments was averaged by students using interactive problem-solving methods by means of computers, than students using conventional methods (See McKeown 1976; Groomer 1981; Freedman 1981). But other studies show performance being no different or even worse when using computers (See Plumly et al 1995; Marriott 1994). A limitation of these research projects is that it is based on conventional measures of student performance, which does not necessarily reflect the specific learning objectives achieved with computers (Boyce 1999).

As to student attitudes, educators cannot assume that students' attitudes towards the use of computers are constant. According to Borthick and Clark (1987) initial enthusiasm waned as students became more computer literate.

\section{Issues related to the introduction of computers in the learning process}

There are necessarily many issues to be considered when implementing computers in the learning process. The students must not see the computer as an add-on, but as an integral part of the course and the learning process (Gelinas et al 2001). The practical computer classes must be a valuable experience to the students and therefore represent a significant portion of the course grade (Gelinas et al 2001). The time involved; the high costs (for example of hardware); more computing time versus more time spent on other courses such as law and finance; and the relevance of the software in the learning process must be considered (Er \& Ng 1989).

There is the danger that students de-emphasize the learning of important subject-related concepts and make greater efforts in computer projects (Togo \& McNamee 1995). It should also be borne in mind that the computer cannot completely replace the need for traditional face-to-face teaching. Because this research project's main objective is to determine the influence of incorporating audit software in the syllabus of computer auditing students, it is important to remember that students' learning abilities should be enhanced through this introduction.

\section{Computers and auditing education}

Computer auditing is a crucial part of the auditing students' curricula. In practice, audit software is used in the execution of audit projects. Although the use of computers is irrelevant to the learning of basic accounting and auditing concepts, in practice the accountant needs to deal with computer-based accounting information systems, and the auditor with their subsequent auditing ( $\mathrm{Er} \& \mathrm{Ng} 1989$ ). It becomes essential that auditing students be exposed to the practical use of audit software.

Many researchers in the field have described different ways of incorporating accounting information systems and computer auditing in the learning process (See for example, Bhaskar 1983; Walsch 1986; Engle \& Joseph 1986; Chandler 1984; Vasarhelyi \& Lin 1985). It should also be noted that many auditing students will not necessarily end up practicing auditing, but will find themselves in the private sector, for example industry, and the public sector (Tinker \& Koutsoumadi 1997). These students will also be in need of an computer technology background.

In 1986 the Bedford Committee, constituted by the American Accounting Association, in its report titled Future accounting education: preparing for the expanding profession, indicated that the accounting profession would require major re-orientation in the future. One of the issues that had to be addressed was the creative use of computer technology in the classroom (Basu \& Cohen 1994).

Bhaskar (1983) classified the use of computers in accounting courses into three categories, namely, computer science - the programming of software, computers as computational tools - assisting or 
performing numerical data processing; and computer aided instructions - using the computer as the medium of instruction.

Bhaskar's above classification of computer science (programming) as described, has evolved into a specialised field, performed by programmers. The need for accountants and auditors to be competent in this area has decreased significantly. The second and third classifications can however be applied to auditing education through the use of auditing software packages.

An example of the benefits of using the computer as a computational tool for auditing students was proven in a study conducted in 1985 at the University of Texas. The study indicated that students fail to understand the core of sampling techniques (a part of the auditing syllabus) because they are overly preoccupied with number crunching and mathematical formulas. A microcomputer software package was developed in teaching variable sampling, which resulted in improved students' self-assessment, confidence in using sampling and examination performances. The improved performance of the students can be attributed to the introduction of computer software that assisted students with the learning process (Anderson et al 1988).

Baskar's third category was also successfully proved through a case study, Norwood Office Supplies Inc. developed by Bentley College in the United States of America (Gelinas et al 2001). Audit Command Language $(A C L)$ audit software was integrated into the financial statement auditing class. This case study addressed two of the core competencies identified by the American Institute of Certified Public Accountants in their CPA vision project (AICPA 1999). This report indicated how CPAs should position themselves as value-added professionals in the business world. Two of the most important competencies featured in the report are being technologically adapted; and disposition of strategic and critical-thinking skills. The ACL software used is an example of a technological advance integrated into their daily praxis by many auditors to improve performance.

Auditing, in contrast to accounting, relies heavily on judgment and decision-making. As subjective and risk-based approaches become more critical to the auditor, and judgment and decision-making became an integral part of audit education, it was noted that complex real-world simulation was needed to address these new demands in the education process (Knechel 2000). These complex simulation can be created using computer software.

Examples of such initiatives include SCAD: a simulated case for audit decision making as developed by Felix et al, the Excellence in audit education programme developed by PricewaterhouseCoopers in
1998 and the Mathra Tool Inc case study (Splettstoesser 1999).

\section{Summary of literature review}

The literature study clearly showed that there is a direct link between the needs of the auditing profession, auditing education and computer technology. Although the literature reviewed clearly confirms this link, very little information was found from the students' perspective. After a thorough literature search, scrutinising both local and international publications, various articles indicated an improvement in student performance after the introduction of software (Weil et al 2001; Davis 2002; Gelinas 2001; Anderson 1988). It was noted that these studies said very little from a student's perspective or the studies focused on student's perspectives where the course was introductory accounting (Weil et al 2001). The lack of research on the use of audit software as a benefit to computer auditing students forms the motivation for this study.

\section{RESEARCH METHOD}

Based on various requests by students of the University of Pretoria to narrow the gap between the theory of computer auditing and the practical application of it, it was decided to implement practical classes to teach students to use the computer as an audit tool. Caseware, a software programme for working papers, was used to introduce students at the second year level to the computer as an audit tool. Working papers are included in the syllabus of second year auditing students.

At the third year level, Audit Command Language $(A C L)$ was incorporated to teach the use of technology in the auditing of data files. The first semester of auditing in the third year deals exclusively with audit sampling, auditing in a computerized information systems environment and computer-assisted auditing techniques. All of these topics are addressed by ACL in some way or another.

ACL can be used to view, explore and analyse data, and report on the results. It can access data in diverse formats and on various types of storage devices. The programme can also be used to verify the output of applications where there is a lack of confidence in the original data or where the application might not be functioning correctly (ACL 1999). An advantage to the third year students is the fact that ACL includes a module on statistical sampling for audit purposes.

As a result of the need identified and laid out in detail in the literature review, this study focuses on the benefits derived (if any) by auditing students of the University of Pretoria from the use of $A C L$ at the third 
year level. The reason for this decision is the fact that students are only introduced to the theory of computer auditing in the third year, and can therefore indicate if they benefit from a practical application related to their theoretical studies.

\section{Data collection}

In 2001 a survey was conducted among third year students to determine the benefits derived from the use of ACL as an add-on to the theoretical course. The survey had the format of an anonymous questionnaire. The survey was repeated in 2002. It should be noted however that in 2002 the ACL course was optional for students. Of the 2002 third year students $68 \%$ voluntarily chose to do the ACL course. A fact that should be taken into account is that $8 \%$ of the 2002 group of students were repeating the subject and completed the ACL course in 2001. If these students are eliminated from the 2002 group of students eligible for entering the voluntary $\mathrm{ACL}$ course in $2002,72 \%$ of students chose to do ACL.

In both 2001 and 2002, 115 third year students completed the anonymous questionnaire consisting of eight questions. The questionnaire allowed for additional comments from students. All students attending a lecture at the end of the semester were asked to complete the questionnaire. The fact that 115 questionnaires were received back in both years is purely coincidental.

\section{Data analysis}

\section{Method used}

The two questionnaires used in the 2001 and 2002 survey were identical. For the purposes of this study the results obtained per question will be compared and discussed. The reason for the comparison between the 2001 and 2002 results is the population difference. During 2001 the course was compulsory for all students, while the 2002 group enrolled voluntarily. The results for the two years might differ because of this fact.

\section{Results and discussion}

Question 1: In comparison to other themes dealt with in the auditing syllabus, how would you rate the section on computer auditing?

\begin{tabular}{|l|c|c|}
\cline { 2 - 3 } \multicolumn{1}{c|}{} & $\mathbf{2 0 0 1}$ & $\mathbf{2 0 0 2}$ \\
\hline More difficult & $25 \%$ & $19 \%$ \\
\hline Similar level & $55 \%$ & $54 \%$ \\
\hline Easier & $20 \%$ & $27 \%$ \\
\hline
\end{tabular}

The reason for including this question was to determine the students' general conception of the use of computers in the auditing field.

The results indicate that most students are found computer auditing on a similar level as the other themes dealt with in the auditing syllabus (55\% in 2001 and 54\% in 2002). Students were exposed to the theory of auditing from their second year. The theory covered in third year auditing deals with the application of the theory in a computer environment. It is most likely that to obtain a benefit from using audit software, the student first has to be comfortable with the environment in which the software is to be applied. The 2002 results showed an even greater increase in this tendency. The likely reason for this is the fact that computers are part of our daily lives, and most students were exposed to computers and computer terminology at an early stage. Therefore students could focus on integration and interpretation of difficult computer auditing terminology, rather than the technical side of computers themselves.

Question 2: How would you describe your level of knowledge regarding computer technology and systems from a non-audit point of view?

\begin{tabular}{|l|c|c|}
\cline { 2 - 3 } \multicolumn{1}{c|}{} & $\mathbf{2 0 0 1}$ & $\mathbf{2 0 0 2}$ \\
\hline Excellent & $7 \%$ & $7 \%$ \\
\hline Average & $80 \%$ & $83 \%$ \\
\hline Poor & $13 \%$ & $10 \%$ \\
\hline
\end{tabular}

Knowledge of computer technology and systems forms the basis for computer auditing as auditing takes place through the computer. To successfully understand the auditing concepts in computer auditing, one must be familiar with the computer technology environment. The motivation for including this question was to identify the students' levels of knowledge of this.

In 2001 and 2002 approximately 6\% of the respondents were students who were registered for the degree BCom (Informatics). These students probably indicated their knowledge level as excellent, as their course ensures that they are technically well grounded. The majority of students indicated their knowledge as average in both years. The slight growth in 2002 can be attributed to the fact that the respondents voluntarily enrolled for the ACL course. One would expect students with an average to excellent computer technology knowledge base to be more willing to enrol in order to expand their computer technology knowledge.

A further reason for the increase in the average-group is probably the fact that the 2002 students were the first group to attend a compulsory basic computer 
skills course in their first year. This course is compulsory for all first year students enrolling at the University of Pretoria since 2000

Question 3: To successfully study computer auditing, which of the following best describes your opinion on the subject?

20012002

\begin{tabular}{|l|c|c|}
\hline A computer background is needed & $31 \%$ & $25 \%$ \\
\hline A computer background is helpful & $63 \%$ & $70 \%$ \\
\hline A computer background is unnecessary & $6 \%$ & $5 \%$ \\
\hline
\end{tabular}

This question was included in the survey to link the knowledge of students about computer technology and systems to that of computer auditing. The results prove that students thin that computer technology and systems knowledge is beneficial in studying computer auditing.

Of the respondents in 2001 (2002) 94\% (95\%) indicated an computer technology background is needed or helpful for the successful completion of the course on computer auditing. The fact that the majority of students indicated that an computer technology background is helpful, but not necessarily required, is an area of concern. It might indicate that students do not properly understand the interrelationship between the auditing process and what is being audited.

Question 4: Do you think there is a gap between the theory you study and the practical application thereof?

\begin{tabular}{|l|c|c|}
\cline { 2 - 3 } \multicolumn{1}{c|}{} & $\mathbf{2 0 0 1}$ & $\mathbf{2 0 0 2}$ \\
\hline Yes & $61 \%$ & $62 \%$ \\
\hline No & $39 \%$ & $38 \%$ \\
\hline
\end{tabular}

A general feeling is perceived amongst practitioners that graduate students have a very strong theoretical basis, but experience difficulty in applying this theoretical basis in practice. This perception is based on the authors' regular communication with practitioners about their perception on the work-readiness of students. This question gives a student perspective on the problem.

The survey indicated that $61 \%$ (2001) and $62 \%$ (2002) of respondents confirmed that this problem does exist. Computer auditing lends itself to addressing this problem because of the availability of various computer audit software packages which can be successfully incorporated in the learning process, as was done at the University of Pretoria.
Question 5: Did the course in ACL improve your understanding of the theory?

\begin{tabular}{|l|c|c|}
\cline { 2 - 3 } \multicolumn{1}{c|}{} & $\mathbf{2 0 0 1}$ & $\mathbf{2 0 0 2}$ \\
\hline Yes & $68 \%$ & $52 \%$ \\
\hline No & $32 \%$ & $48 \%$ \\
\hline
\end{tabular}

As indicated in the discussion of question four, narrowing the gap is essential. This question was included to determine whether ACL was able to assist students in narrowing the gap between theory and practice.

Positive results were obtained in 2001 and can be attributed to the fact that the ACL course was compulsory for students in that year. Students with limited or poor computer technology knowledge were compelled to take the course and familiarise themselves with the practical implementation of theoretical concepts in an computer technology environment.

In the 2002 survey the results were less satisfactory. A number of reasons could be adduced. Firstly, the fact that the course was voluntary might have caused students with a poor to limited computer technology knowledge to avoid the course. This group would have benefitted the most from the course. Secondly, comments received during the 2002 survey indicated that the presenter lacked competency in presenting the course. The University of Pretoria encourages computer courses but there are limited resources for presenting these non-mainstream courses. An Honours student, who completed the course the previous year, was used to present the course. The presenter (as in 2001) had no formal training or experience in lecturing.

Question 6: Did the course in ACL improve your computer skills?

\begin{tabular}{|l|c|c|}
\cline { 2 - 3 } \multicolumn{1}{c|}{} & $\mathbf{2 0 0 1}$ & $\mathbf{2 0 0 2}$ \\
\hline Yes & $79 \%$ & $39 \%$ \\
\hline No & $21 \%$ & $61 \%$ \\
\hline
\end{tabular}

The question was included to determine if basic computer skills were improved through the ACL course in 2001 as an additional benefit to the course for students. It should be noted that the 2001 student group were not necessarily exposed to computers in courses taken other than auditing.

In contrast to the 2001 group, the 2002 group of students was the first to reach the third year after the compulsory introduction of basic computer classes for all first year students at the University of Pretoria. We attribute the $40 \%$ decrease in positive responses to this question directly to the introduction of the first year computer literacy courses. 
Question 7: Do you think ACL will improve your career opportunities?

\begin{tabular}{|l|c|c|}
\cline { 2 - 3 } \multicolumn{1}{c|}{} & $\mathbf{2 0 0 1}$ & $\mathbf{2 0 0 2}$ \\
\hline Yes & $93 \%$ & $83 \%$ \\
\hline No & $7 \%$ & $17 \%$ \\
\hline
\end{tabular}

In the past, graduate students and employers contacted the University and indicated that the ACL course enhanced the marketability of the students. With this in mind, the question was incorporated to determine if students are aware of the positive benefits that the ACL course could have for their future careers.

Although a slight decrease in positive perception was found in 2002, the majority still feel that ACL will improve their marketability. This perception can also be attributed to career advertisements for auditors, which usually recommend knowledge of an auditing computer software package.

Question 8: Would it benefit you if more time were spent on the practical applications available for computer auditing?

\begin{tabular}{|l|c|c|}
\cline { 2 - 3 } \multicolumn{1}{c|}{} & $\mathbf{2 0 0 1}$ & $\mathbf{2 0 0 2}$ \\
\hline Yes & $81 \%$ & $90 \%$ \\
\hline No & $19 \%$ & $10 \%$ \\
\hline
\end{tabular}

The current ACL course consists of a two-hour lecture every second week, which equals 14 hours of $A C L$ training in the 14-week computer-auditing semester. Through this question it was hoped to determine whether this was sufficient for students.

From the results it is clear that students would like more exposure to practical applications for computer auditing. The $9 \%$ increase towards more exposure, can be attributed to the fact that 2002 students voluntarily took the course and could be considered committed to gaining more knowledge related to computer technology.

\section{SUMMARY, CONCLUSIONS AND RECOMMENDATIONS}

This study aimed to evaluate the students' perspective on the benefits, if any, for third year auditing students at the University of Pretoria, derived from the incorporation of practical computer training in an audit software package, in their syllabus.

A review of the literature on the topic of computers in the auditing environment, computers in the learning process and computers and auditing education was presented as the background to the questionnaire examined. Although numerous research studies have been done on the topics, very little was found about the students' perspective on incorporating computers into the learning process, especially in the auditing field. The study aimed to address this shortcoming by the compilation of a questionnaire completed by third year auditing students during 2001 and 2002. During 2001 the practical computer classes presented were compulsory for all third year auditing students, while the 2002 group voluntarily chose to do the practical course, thereby eliminating less committed computer auditing students.

The findings from a survey of the literature on the topic have shown that the global market has changed dramatically, and with that the needs of professionals and society. Against this background it still seems to be the case that university departments generally do not prepare graduates for the working environment. The move from compulsory ACL training for all students, to training on a voluntary basis is regrettable in this light. Personal enquiries made at other universities in the Gauteng province of South Africa indicated that there was no subject-related computertraining given to auditing students at these institutions.

Although the basic computer technology knowledge of students is increasing as a result of increased computer accessibility, the need for subject-related computer training still exists. The study has sought to show that students benefit from the $A C L$ training. Students confirmed that they believed there was a definite gap between the theory of computer auditing and the practical application of it. The 2002 results showed a slight decrease in this perception, but the majority of students still felt that $A C L$ narrowed the gap.

Students' were very aware of the auditing professions' needs, and specifically the importance of being job-ready. As ACL is widely used by practitioners in South Africa, the training of students in this software programme will help to solve the problem of graduates not being prepared for their workplace careers.

The study showed that students are willing to sacrifice more of their time to include practical training classes because they are aware of the beneficial impact the training has on their understanding of the subject, as well as their future careers. On the one hand students are clients of the University, while on the other, they also represent the product produced by the University. The fact that computer training as part of the auditing course, is not currently seen as part of the formal curriculum is deplorable.

From the analysis of the results, it can be concluded that the introduction of the use of the computer and related audit software in computer auditing training, students have positive perceptions and view its 
introduction as a highly beneficial learning resource. This teaching approach moves away from the old method of auditing around the computer (ignoring the computer by only comparing input and output) to a more hands-on (using the computer as part of the audit) learning experience.
It is recommended that the University of Pretoria and other tertiary institutions reconsider their resource allocation for subject-related computer education. This would be in the best interests of tertiary institutions, students and the business community.

\section{REFERENCES}

Accounting Education Change Commission (AECC) 1992. The first course in accounting - position statement. Issues in Accounting Education 7(2):249-251, Fall 1992.

ACL for Windows 6.5 1999. Workbook. ACL Services Limited, Vancouver, Canada.

Ahadiat, N 1992. A study of work values of computer education in accounting. Computer Education Vol 19, Issue 4:369-380.

American Institute of Certified Public Accountants 1999. Focus on the horizon, the CPA profession in 2011. New York.

American Institute of Certified Public Accountants. 1999. The Newsletter of the AICPA Standards Division. New York, October 1999.

Anderson, U, May, R G \& Miles, C A 1988. Variables sampling software: development and classroom testing. Issues in Accounting Education 3(1):156-173.

Bagranoff, N A 1993. Adopting commercial software in the accounting classroom: a focus on learning Journal of Accounting Education Vol 11:275- 286.

Basu, P \& Cohen, J 1994. Learning to learn in the accounting principles course: outcome assessment of an integrative business analysis project. Journal of Accounting Education 12(4):359-374.

Bhasker, K N 1983. Computers and the choice for accountancy syllabuses. Accounting and Business Research Vol 13, Spring 1983:83-93.

Bonner, S E 1999. Choosing teaching methods based on learning objectives: an integrative framework. Issues in Accounting Education Vol 14, February 1999:11-39.

Borthick, AF \& Clark, R L 1987. Research on computing in accounting education: opportunities and impediments. Issues in Accounting Education 2(2):173-192.

Boyce, G 1999. Computer-assisted teaching and learning in accounting: pedagogy or product? Journal of Accounting Education Vol 17, December 1999:191-220.

Chandler, J S 1984. A course on the management of the systems development process with hands-on computing. Journal of Accounting Education Vol 2, Spring 1984:99-110.

Davis, M 2000. Using a computerized case study to teach computer auditing: the reasons, the approach and the student response. Managerial Auditing Journal Vol 15(5):247-252.

Engle, T J \& Joseph, G W 1986. A successful approach to integrating computer assignments in the accounting information systems course in a manner that complements theoretical readings and classroom discussions. Journal of Accounting Education Vol 4, Fall 1986:141-146.

Er, M C \& Ng, A C 1989. The use of computers in accountancy courses: a new perspective. Accounting and Business Research Vol 19(76):319-326.

Evans, J R 1986. Creative thinking and innovative education in the decision sciences. Decision Sciences 17:250262.

Felix, W L, Jr, May, R G, Niles, M S, Gillespie, J D \& Andrus, J No date. SCAD: a simulated case for audit decision making. New York, NY: Irwin/McGraw-Hill.

Freedman, M E 1981. The effect on achievement of using the computer as a problem-solving tool in the intermediate accounting course. The Accounting Review January 1981:137-143.

Gelinas, U J, Levy, E S \& Thibodeau, J C 2001. Norwood office supplies inc: a teaching case to integrate computer-assisted auditing techniques into the auditing course. Issues in Accounting Education Vol 16. November 2001:603-636.

Groomer, S M 1981. An experiment in computer-assisted instruction for introductory accounting. The Accounting Review October 1981:934-941.

Guthrie, E R 1959. Association by contiguity. Psychology: A study of a Science 2:58-195.

Hermanson, D R, Hill, M C \& Ivancevich, D M 1999. How governmental and internal auditors are adapting to changes in information technology. Internal Auditing July 1999.

International Federation of Accounts (IFAC) 1996. International Auditing Guidelines. International Auditing Practices Committee, New York.

Kiger, J E \& Scheiner, J H 1997. Auditing. Second edition, Houghton Mifflin, Boston. 
Knapp, M \& Knapp, C 2000. Perry drug stores incorporated: accounting and control issues for inventory in a retail environment. Issues in Accounting Education 15:237-255.

Knechel, W R 2000. Behavioral research in auditing and its impact on audit education. Issues in Accounting Education 15(4) November 2000.

Lanza, R B 1998. Take my manual audit please. Journal of Accountancy Vol 185, June 1998:33.

Marriott, N 1994. The effectiveness of using spreadsheets to teach financial accounting. Journal of Accounting Education 3:137-150.

McKeown, J C 1976. Computer-assisted instruction for elementary accounting. The Accounting Review January 1976:123-130.

Nearon, B H 2001. Research opportunities in information technology auditing: addressing recommendations of the panel on audit effectiveness. The CPA Journal Vol 71. April 2001:14.

Nickerson, R S, Perkins, D N \& Smith, E E 1985. The teaching of thinking. Hillsdale: Lawrence Erlbaum Associates, New Jersey.

Nisbett, R \& Ross, L 1980. Human inference: strategies and shortcomings of social judgment. Engelwood Cliffs: Prentice-Hall, New Jersey.

Paukowits, F 1998. Mainstreaming CAATS. Internal Auditor 55(1) February 1998:19.

Pettigrew, T 1991. Putting the IT into auditing. The Accountant's Magazine Vol 95 April 1991:49.

Plumly, L W, Ray, H W \& McKinney, J E 1995. An alternative means of student assessment in accounting courses. Journal of Accounting and Computers Vol 11, Fall 1995.

Pricewaterhouse Coopers 1998. Excellence in auditing education. New York.

Silver, E A 1985. Research on teaching mathematical problem solving: some under-presented themes and needed direction. Teaching and learning mathematical problem solving. Hillsdale: Lawrence Erlbaum Associates, New Jersey, 247-266.

South African Institute of Chartered Accounts (SAICA) 1998(a). SAICA handbook volume two, South African Auditing Standard 001 . Kengray, South Africa.

South African Institute of Chartered Accounts (SAICA) 1998(b). SAICA handbook volume two, South African Auditing Standard 401, Kengray, South Africa.

South African Qualifications Authority (SAQA) 1995. Act number 58 of 1995. Government Gazette, Number 1521 (4 October 1995). Government Printer, Pretoria.

Splettstoesser, I B 1999. Information systems controls and auditing: Mathra Tool Inc. Issues in Accounting Education 14(2):285-303.

Theron, H J 1999. Realities of auditing education. South African Journal of Higher Education 13(1):113-121.

Tinker, T \& Koutsoumadi, A 1997. A mind is a wonderful thing to waste: think like a commodity, become a CPA. Accounting, Auditing and Accountability Journal 10(3):454-467.

Togo, D F \& McNamee, A H 1995. Computer integration into the accounting curriculum: learning benefits, problems and guidelines. Journal of Accounting Education 13:49-158.

Vasarhelyi, M A \& Lin, W T 1985. EDP Auditing instruction using an interactive generalized audit software. Journal of Accounting Education 3, Fall 1985:79-89.

Waller, T C \& Gallum, R A 1985. Micro-computer competency requirements in the accounting industry: a pilot study. Journal of Accounting Education Vol 3, Fall 1985:31-40.

Walsh, $\mathrm{H}$ 1986. Empirical evidence on internal control in minicomputer-based accounting information systems. Accounting and Business Research Vol 16, Summer 1986:227-233.

Watne, D A \& Turney, P B B 1990. Auditing EDP systems. Second edition. Prentice Hall, New Jersey.

Weil, S, Clark, M, Wegner, T \& Oyelere, P 2001. Student perceptions of the pedagogical features of a computeraided learning programme in introductory accounting. South African Journal of Accounting Research 15(1):1-23.

Wertheimer, M 1995. Productive thinking. Second edition. Harper and Row. 